\title{
86
}

\section{Use of Internet facilities in education}

\author{
Jaroslav Sklenar \\ University of Malta \\ Department of Computer Information Systems \\ Msida MSD 06 \\ Malta \\ jskl@cis.um.edu.mt
}

\begin{abstract}
Hypertext documents offer completely new opportunities in all aspects of communication both among humans and between humans and computers. The poster shows typical screens of a web document that is used as a means of communication between a lecturer and a quite big population of students involved in various courses at the University of Malta. The spectrum of students goes from the Junior College (sixth form) through various undergraduate courses to candidates preparing for their B.Sc. theses.
\end{abstract}

\section{KEYWORDS Education, World Wide Web, INTERNET}

\section{INTRODUCTION}

We all know how the mass use of all Internet based facilities has changed our lives in recent years. There are many aspects of this phenomenon that has both positive and negative consequences (recently my son has downloaded a complete "Terrorist Handbook" with detailed guides how to prepare explosives and similar stuff). Whatever are the consequences, the Internet is here, it will be here, and young people will use it definitely more and more. So the only thing we should do is to make the best possible use of it.

\section{TEACHER - STUDENT}

The most typical way of using web documents in education is probably distribution of notes, extracts of lectures, various charts, worksheets, demonstration programs and sometimes complete textbooks. The advantages are obvious. A lecturer can transfer a lot of data to practically unlimited number of recipients in a very short time. What is maybe even more important is the possibility of keeping materials permanently up to date. All changes are done only once in the original document in the home directory of the owner of the page, all recipients get automatically a latest updated version at each connection. This is broadcasting.

Web documents can also complement e-mail in point to point communication. Very often there are problems with attachments to e-mail messages. In the UNIX environment the attachment has to be often converted manually. If the message is not saved properly, it must be retransmitted. All these can cause troubles, especially if there is a very heterogeneous group of potential recipients (from hackers that are totally in to beginners, who have never used computers before). An alternative way is a simple special purpose document (maybe with a not standard extension to its name) that contains a reference (URL) to the file to be transferred together with a guide how to use it. The name of the document is then given (for example e-mailed) to the recipient or a group of recipients. The file is permanently available, the transfer is very easy even for

Human-Computer Interaction: INTERACT'97 S. Howard, J. Hammond \& G. Lindgaard (editors)

Published by Chapman \& Hall @IFIP 1997 
complete beginners, and again its updating (maintenance) is very easy. When not used any more, both the file and the document should be deleted.

\section{STUDENT - TEACHER}

This flow of information is very useful for all teachers. We all need a sort of feedback from students. Especially at lower grades (in my case at the sixth form college) there is a permanent danger, that students might give up in certain more demanding topics. All teachers know how difficult it is to obtain this type of information. When asked in the class, many students are because of various reasons not willing to talk frankly about their problems. Of course personal contact lessons help a lot, but time is a very limiting factor. Here simple e-mail can help very much. First of all, the tutor must get student's confidence, that all the information supplied will be used by the educator only and will not be revealed to other students under any circumstances. Then it is possible, to get very useful ideas and hints from students. When writing e-mail messages at home, students can concentrate, and so they tend to be more open. This is another reason why all Web documents should have an option to e-mail to the author.

Forms that can be created by the facilities of the HTML language offer another way how to obtain information from students, but their preparation is not an easy task to do and they actually just replace traditional questionnaires.

\section{STUDENT - STUDENT}

All teachers know what a powerful tool is proper motivation. The possibility of being adequately rewarded makes many people (not only students) work very hard. A very efficient way of rewarding students is a sort of public appreciation of their abilities. For this purpose a Web document can be very useful. For example in my Web page there is something I call "Student's corner". It is used for presentation of nice solutions to various problems, so far mostly as a place to show Turbo Pascal programs that are either interesting, not traditional, have educational value, or have simply a nice graphics. (We use Turbo Pascal both at the sixth form and in most under graduate courses).

Of course all presented programs are available to all students (to be downloaded in compressed form). It is very important to make it very clear since the very beginning, that a place like that can under no circumstances be used for any commercial purpose. There is this danger, because many students - especially the best ones - who contribute with their programs are actively involved in various software companies already during their studies. So an attempt to use a teacher's page for advertising is logical.

\section{TEACHER - TEACHER}

The name of this chapter is not the best one, but it was very tempting to use the fourth combination. In fact there are many other ways how Internet facilities can be used in research, organization of conferences (like this one), and generally in all activities that are based on transfer of information. Actually it is more difficult, but definitely shorter to list activities, that can not benefit from Internet facilities like e-mail, Web documents, News groups, File transfer, etc.

Among many others, Internet has helped very much in communication between authors of software products and their users. It used to be a very demanding task to keep all registered users informed about the latest development and especially to distribute patches, adds on, and new versions of the product. Internet offers an elegant solution to this problem. In fact practically all commonly used products have their home pages, that contain everything the company wants the users to know. Even for commercial products you can often find various adds on and updates (like for example Internet Assistant for Microsoft Word).

The poster shows typical screens from the home page of the program PetriSim, that is an editor and simulator of Petri Networks with the possibility to create user simulation models in Turbo Pascal. There are several demo examples, that are all full scale editors and simulators of Petri networks. For more see my home page: http://www.cis.um.edu.mt/ jskl 